\title{
Atrioventricular valve surgery: Restoration of the fibrous skeleton of the heart
}

Edward Buratto, MBBS, PhD, FRACS, ${ }^{\mathrm{a}, \mathrm{b}, \mathrm{c}}$ and Igor E. Konstantinov, MD, PhD, FRACS ${ }^{\mathrm{a}, \mathrm{b}, \mathrm{c}, \mathrm{d}}$

Millions of years of relentless evolution have shaped the human heart into a durable and incredibly efficient pump. This high durability and efficiency are impossible without the normal fibrous skeleton of the heart. To achieve optimal results in our surgical work, we must emulate the work of nature as closely as possible. A perfect example of this would be surgery for the atrioventricular valve (AVV). Although the results of AVV repair have improved over time, AVV regurgitation remains a formidable challenge, particularly, in the univentricular circulation. ${ }^{1-7}$ Although more than $20 \%$ of patients with univentricular circulation develop moderate or greater AVV regurgitation of mitral, tricuspid, or common AVV by 20 years, the rate of failure of common AVV in the univentricular circulation is greater than $50 \%$ by 20 years. ${ }^{3}$ Furthermore, it is unequivocal that AVV regurgitation is associated with poorer survival in patients with univentricular circulation. ${ }^{5}$ Achieving a durable repair of AVV, including that in common AVV, is often difficult in univentricular circulation, especially in patients with right ventricular dominance. ${ }^{3}$ In this focused review, we summarize the recent literature on the outcomes of AVV surgery in patients with univentricular circulation with emphasis on the importance of restoring the fibrous skeleton of the heart.

\section{NORMAL AND MALFORMED FIBROUS SKELETON OF THE HEART}

The structurally normal human heart has a welldeveloped fibrous skeleton (Figure 1, A) that provides support for the myocardium and the valves. The aortic valve is in fibrous continuity with the mitral and tricuspid valves. The confluence of these 3 valves forms the central fibrous body. This structure is malformed in the spectrum of patients with common AVV. Patients with common AVV and balanced ventricles (Figure 1, $B$ ) or various degrees of right

From the ${ }^{\mathrm{a} D e p a r t m e n t ~ o f ~ C a r d i a c ~ S u r g e r y, ~ R o y a l ~ C h i l d r e n ' s ~ H o s p i t a l, ~ M e l b o u r n e, ~}$ Australia; 'Department of Paediatrics, University of Melbourne, Melbourne, Australia; 'Heart Research Group, Murdoch Children's Research Institute, Melbourne, Australia; and ${ }^{\mathrm{d}}$ Melbourne Children's Centre for Cardiovascular Genomics and Regenerative Medicine, Melbourne, Australia.

Received for publication March 13, 2021; revisions received March 13, 2021; accepted for publication March 16, 2021; available ahead of print May 7, 2021.

Address for reprints: Igor E. Konstantinov, MD, PhD, FRACS, Royal Children's Hospital, Flemington Rd, Parkville 3052, Australia (E-mail: igor.konstantinov@rch. org.au).

J Thorac Cardiovasc Surg 2021;162:360-5

$0022-5223 / \$ 36.00$

Crown Copyright $\odot 2021$ Published by Elsevier Inc. on behalf of The American Association for Thoracic Surgery

https://doi.org/10.1016/j.jtcvs.2021.03.128

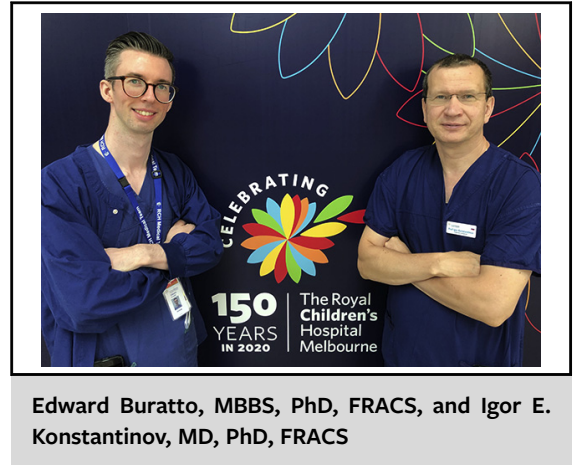

\section{CENTRAL MESSAGE \\ Restoration of the fibrous skel- eton of the heart appears to be crucial for durable repair of common AVV in univentricular circulation.}

ventricular hypoplasia (Figure 1,C) still have a normally formed aortic valve. In contrast, in patients with common AVV and hypoplasia of the left ventricle with various degrees of aortic valve hypoplasia, the fibrous skeleton is even less supported (Figure 1,D). The extreme end of the spectrum of fibrous skeleton maldevelopment would occur in patients with aortic atresia with common AVV. Unsurprisingly, it has been demonstrated that right ventricular dominance is a risk factor for death ${ }^{8}$ and AVV insufficiency. ${ }^{3}$ Repair of AVV in right ventricle dominant univentricular circulation is notoriously difficult. Thus, patients with right ventricle dilatation and AVV insufficiency may be referred to heart transplantation before an attempt of repair is undertaken. However, even patients with poor single ventricular function may have dramatic improvement when the competence of the AVV is restored. ${ }^{9}$ In contrast, patients with tricuspid atresia have well-formed mitral valve and fibrous skeleton of the heart and rarely have AVV insufficiency. ${ }^{3}$

\section{INCIDENCE OF ATRIOVENTRICULAR VALVE DYSFUNCTION IN PATIENTS WITH SINGLE- VENTRICLE PHYSIOLOGY}

It appears that failure of AVV affects approximately $20 \%$ of patients with single-ventricle physiology by 20 years of 

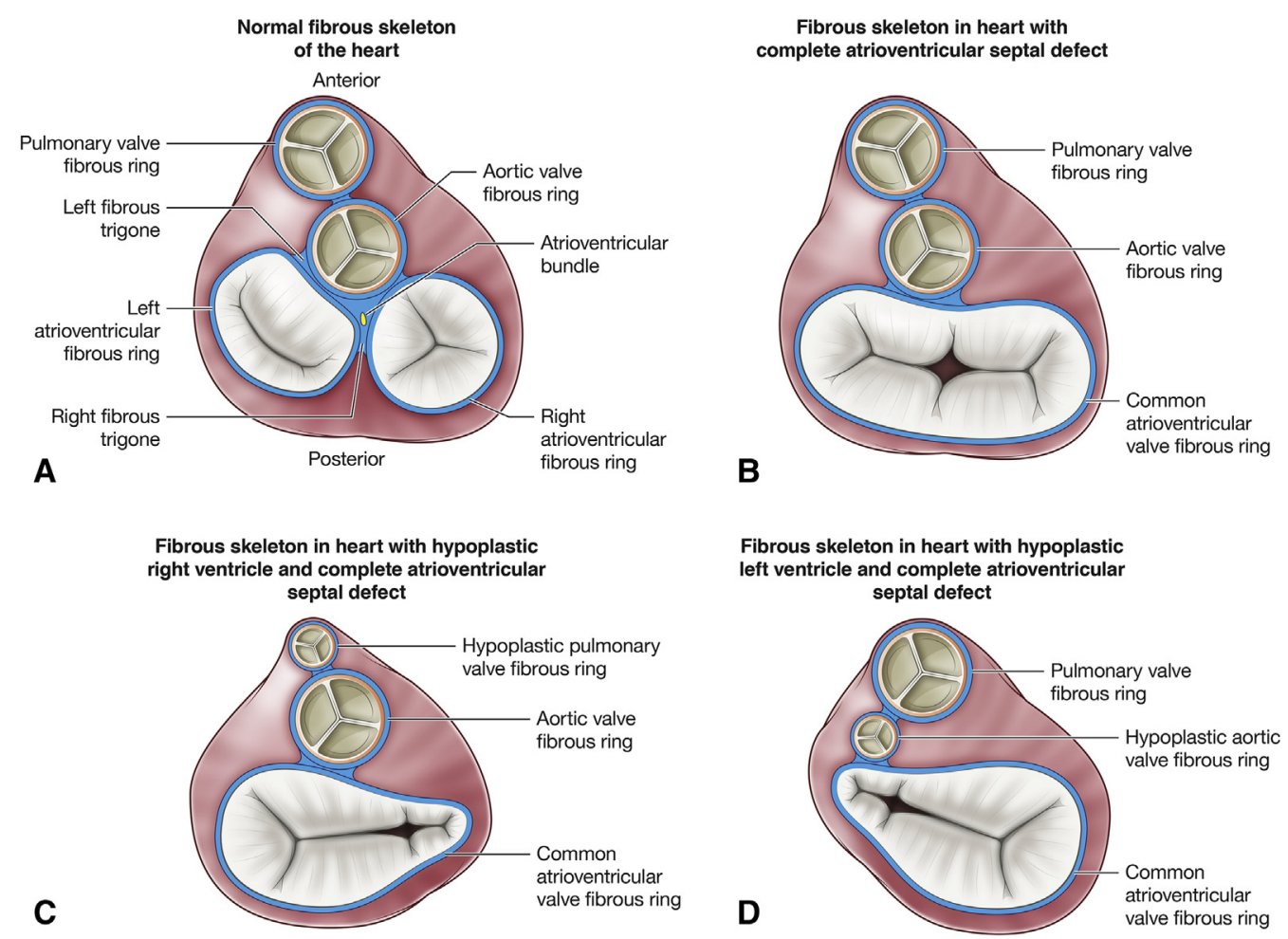

FIGURE 1. Schematic of the fibrous skeleton of the heart. Well-developed fibrous skeleton in normal heart (A). A spectrum of maldevelopment of fibrous skeleton of the heart in patients with complete atrioventricular septal defects with balanced ventricles (B), right-sided hypoplasia (C), and left-sided hypoplasia (D), with extreme end of the spectrum represented in aortic atresia.

age. ${ }^{3}$ Single-ventricle palliation is performed for a broad range of congenital anomalies, and the rate of AVV failure is, predictably, related to the morphology of the AVV and, thus, to the extent to which the fibrous skeleton of the heart is developed. ${ }^{3,10}$ Consequently, patients with tricuspid atresia have the lowest rate of AVV failure, with $8 \%$ having valve failure at 25 years, because they have a mitral valve as their AVV. The rate of AVV failure is higher in those with mitral atresia reaching $46 \%$ at 25 years. Yet, the highest rate of AVV failure is observed in those with a common AVV, affecting $56 \%$ of these patients by 25 years of age.

\section{OUTCOMES OF UNIVENTRICULAR REPAIR IN PATIENTS WITH COMMON ATRIOVENTRICULAR VALVE}

Great progress has been made in repair of balanced complete atrioventricular septal defect (AVSD) in recent years, with operative mortality reported of $1 \%$ to $3 \%$ and 20 -year survival of approximately $90 \% .^{11-15}$ Conversely, little progress has been made in the surgical management of unbalanced AVSD. Early reports suggested that only onethird of patients could survive to Fontan, and only onehalf of these patients with Fontan circulation went on to be long-term survivors. ${ }^{16,17}$ Recently, we demonstrated that the outcomes of these patients were better than previously thought, with $60 \%$ of patients reaching Fontan completion and a 25 -year survival of $80 \%$ in those patients who reached Fontan completion. ${ }^{1,18}$ We have learned from this experience that it is crucial to have AVV competence to achieve a long-term survival in these challenging patients ${ }^{2}$ as transplantation-free survival of those left with moderate or great AVV insufficiency was approximately $30 \%$ at 2 years after attempted AVV repair. ${ }^{2}$ In sharp contrast, those who had common AVV replacement had $75 \%$ survival at 10 years. $^{2}$ A recently proposed strategy of biventricular recruitment and conversion has been described, but early results appear similar to those achieved with conventional single ventricular palliation, and long-term follow-up is lacking. ${ }^{19}$

In patients with balanced ventricles who undergo complete repair, the risk of AVV reoperation is approximately $25 \%$ at 20 years. ${ }^{11}$ Conversely, in patients with unbalanced AVSD, the rate of AVV reoperation is in the range of $40 \%$ to $50 \%$ at 25 years follow-up. AVV failure in these patients is associated with increased risk of mortality. ${ }^{2,20}$

\section{RESULTS OF ATRIOVENTRICULAR VALVE SURGERY}

\section{Traditional Repair Techniques}

In general, the results of reoperation for AVV regurgitation are not durable across the spectrum of AVSDs. In 
patients with balanced complete AVSD, the freedom from reoperation is approximately $25 \%$ at 20 years. ${ }^{11,13}$ In patients with unbalanced AVSD, the results are even more disappointing with $40 \%$ requiring reoperation by 15 years. ${ }^{1,4}$

Imai and colleagues ${ }^{21}$ reported 28 patients with unbalanced AVSD and univentricular physiology who underwent concomitant AVV repair and Fontan procedure between 1985 and 1998. The techniques used in this series were circular suture annuloplasty and cleft closure, and they reported a decrease in the mean grade of AVVR from 1.8 to 0.6 after repair. This study did not describe early mortality or long-term survival of patients who underwent repair of their common AVV.

Kotani and colleagues ${ }^{22}$ reported 66 patients with singleventricle physiology who underwent AVV repair from 1998 to 2011, of whom 10 patients had common AVV. The mean grade of AVV regurgitation decreased from 2.1 to 1.3 after repair. At 5 years follow-up, freedom from reoperation was $75 \%$, whereas survival was $76 \%$. Significant residual AVV regurgitation on intraoperative echocardiography was associated with increased risk of reoperation.

Laux and colleagues ${ }^{23}$ reported 31 patients with singleventricle physiology who underwent AVV repair between
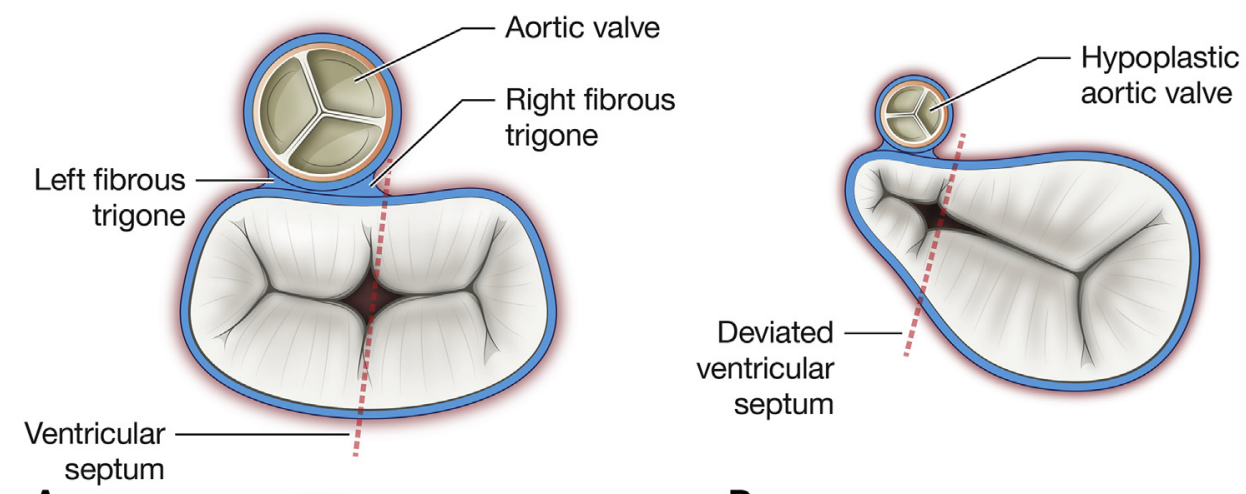

A

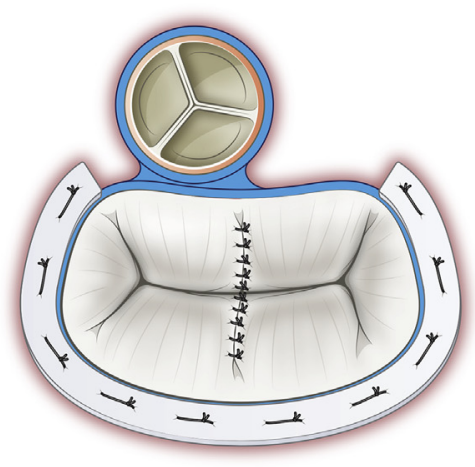

B

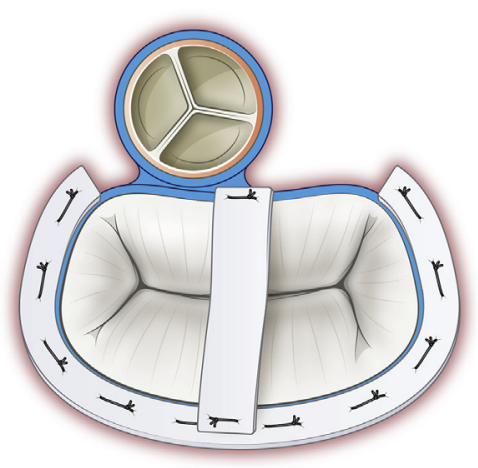

D

E

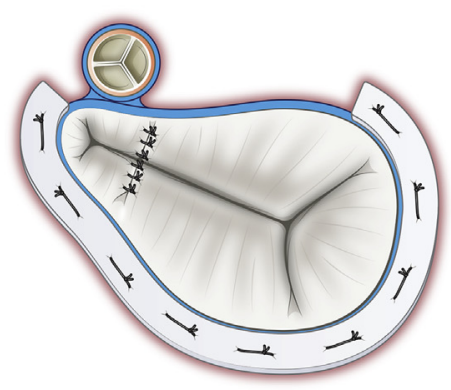

$\mathbf{F}$

FIGURE 2. Schematic of common AVV repair techniques aimed at restoration of fibrous skeleton of the heart in univentricular circulation. Septation of the common AVV in univentricular circulation (A) is not feasible; thus, repair is often limited to annuloplasty and edge-to-edge approximation to achieve good central coaptation and central stabilization (B). To achieve durability of the repair, the fibrous skeleton of the heart should be emulated as close as possible, for instance, with a bridging annuloplasty (C). Common AVV repair in patients with left-sided hyploplasia is particularly difficult, partly due to septal deviation and severe malformation of fibrous skeleton of the heart (D). Thus, in addition to annuloplasty and central stabilization (E), the bridging annuloplasty (F) or complete closure of hypoplastic component of the common AVV is often the only way to ensure long-term durability. 
1998 and 2014, of whom 32\% (10/31) had a common AVV. Using a range of repair techniques including annuloplasty, cleft closure, and edge-to-edge repair, they achieved freedom from AVV reintervention of $62 \%$ at 10 years.

Our group ${ }^{24}$ reported 66 patients with single-ventricle physiology who underwent AVV repair between 1988 and 2010 , of whom $18 \%(14 / 66)$ had a common AVV. Common AVV was a risk factor for reoperation, with freedom from reoperation of only $30 \%$ at 10 years.

Nakata and colleagues ${ }^{25}$ reported 65 patients with singleventricle physiology who underwent AVV repair between 1999 to 2008, of whom 54\% (35/65) had common AVV. Freedom from reoperation on the AVV was $57 \%$ at 5 years.

\section{Closure of the Hypoplastic Component of the Common Atrioventricular Valve}

In patients with significant imbalance of the ventricles, closure of the hypoplastic component of the valve may restore competence without compromising the valve orifice. This may be achieved by suture approximation of the leaflets or use of a patch. Our group ${ }^{26}$ reported 38 patients with Fontan who underwent closure of the hypoplastic component of common AVV between 1975 and 2018 from a binational registry. Freedom from reoperation was $83 \%$ at 18 years.

\section{Restoration of the Fibrous Skeleton of the Heart}

In an attempt to address the high rate of failure observed after repair of common AVV in the univentricular circulation, several groups have described using bridging annuloplasty (Figure 2) in these patients. ${ }^{27-30}$ In this technique, a strip of synthetic material or pericardium is placed transversely across the common valve annulus above the ventricular septum and sutured to the annulus, with the aim of reducing the anteroposterior dimension of the annulus and replicating the normal fibrous skeleton. ${ }^{27-30}$ Although there have only been a small number of studies so far, results appear promising.

Misumi and colleagues ${ }^{31}$ reported 38 patients who underwent common AVV surgery between 1995 and 2012, of whom 27 underwent repair using the bridging technique. They demonstrated a 15-year freedom from reoperation of $45.3 \%$, which was similar to other repair techniques, although with a small number of patients. Furthermore, they found the technique to be reproducible, and they did not need to replace any valves after introduction of the technique.

$\mathrm{He}$ and colleagues ${ }^{32}$ reported 37 patients who underwent repair of common AVV between 2007 and 2018. The bridge technique was used in $51 \%(19 / 37)$ of patients. Use of the bridge technique was associated with superior freedom from common AVV failure at 10 -year follow-up $(62 \%$ vs $35 \%, P=.01)$.

\section{CONCLUSIONS}

Common AVV regurgitation is a challenging problem, especially in the setting of univentricular physiology. Although current repair techniques have a high rate of long-term failure, the ideal technique, which is yet to be determined, should emulate the normal fibrous skeleton of the heart as closely as possible.

\section{Conflict of Interest Statement}

The authors reported no conflicts of interest.

The Journal policy requires editors and reviewers to disclose conflicts of interest and to decline handling or reviewing manuscripts for which they may have a conflict of interest. The editors and reviewers of this article have no conflicts of interest.

\section{References}

1. Buratto E, Ye XT, King G, Shi WY, Weintraub RG, d'Udekem Y, et al. Long-term outcomes of single-ventricle palliation for unbalanced atrioventricular septal defects: Fontan survivors do better than previously thought. J Thorac Cardiovasc Surg. 2017;153:430-8

2. Buratto E, Ye XT, Brizard CP, Brink J, d'Udekem Y, Konstantinov IE. Successful atrioventricular valve repair improves long-term outcomes in children with unbalanced atrioventricular septal defect. J Thorac Cardiovasc Surg. 2017;154 2019-27.

3. King G, Ayer J, Celermajer D, Zentner D, Justo R, Disney P, et al. Atrioventricular valve failure in Fontan palliation. J Am Coll Cardiol. 2019;73:810-22.

4. King G, Gentles TL, Winlaw DS, Cordina R, Bullock A, Grigg LE, et al. Common atrioventricular valve failure during single ventricle palliation. Eur J Cardiothorac Surg. 2017;51:1037-43.

5. Downing TE, Allen KY, Glatz AC, Rogers LS, Ravishankar C, Rychik J, et al. Long-term survival after the Fontan operation: twenty years of experience at a single center. J Thorac Cardiovasc Surg. 2017;154:243-53.

6. Stephens EH, Dearani JA. Management of the bad atrioventricular valve in Fontan...time for a change. J Thorac Cardiovasc Surg. 2019;158:1643-8.

7. Romano JC. Keep it simple: repair of atrioventricular valve regurgitation in patients with a single ventricle. J Thorac Cardiovasc Surg. 2018;155:710-1.

8. d'Udekem Y, Xu MY, Galati JC, Lu S, Iyengar AJ, Konstantinov IE, et al. Predictors of survival after single-ventricle palliation: the impact of right ventricular dominance. J Am Coll Cardiol. 2012;59:1178-85.

9. Perrier SL, Zhu MZL, Weintraub RG, Konstantinov IE. Tricuspid valve replacement in failing Fontan circulation with severe ventricular dysfunction: the road not taken? J Thorac Cardiovasc Surg. 2018;156:e141-3.

10. Moon J, Shen L, Likosky DS, Sood V, Hobbs RD, Sassalos P, et al. Relationship of ventricular morphology and atrioventricular valve function to long-term outcomes following Fontan procedures. J Am Coll Cardiol. 2020;76:419-31.

11. Xie O, Brizard CP, d'Udekem Y, Galati JC, Kelly A, Yong MS, et al. Outcomes of repair of complete atrioventricular septal defect in the current era. Eur J Cardiothorac Surg. 2014;45:610-7.

12. Buratto E, Hu T, Lui A, Wu DM, d'Udekem Y, Brizard CP, et al. Early repair of complete atrioventricular septal defect has better survival than staged repair after pulmonary artery banding: a propensity score-matched study. J Thorac Cardiovasc Surg. 2021;161:1594-601.

13. Fong LS, Betts K, Bell D, Konstantinov IE, Nicholson IA, Winlaw DS, et al Australian CAVSD Study Group. Complete atrioventricular septal defect repair in Australia: results over 25 years. J Thorac Cardiovasc Surg. 2020;159:1014-25.

14. Devlin PJ, Jegatheeswaran A, McCrindle BW, Karamlou T, Blackstone EH Williams WG, et al. Pulmonary artery banding in complete atrioventricular septal defect. J Thorac Cardiovasc Surg. 2020;159:1493-503.

15. Ramgren JJ, Nozohoor S, Zindovic I, Gustafsson R, Hakacova N, Sjögren J Long-term outcome after early repair of complete atrioventricular septal defect in young infants. $J$ Thorac Cardiovasc Surg. 2021;161:2145-53.

16. Drinkwater DC Jr, Laks H. Unbalanced atrioventricular septal defects. Semin Thorac Cardiovasc Surg. 1997;9:21-5.

17. Owens GE, Gomez-Fifer C, Gelehrter S, Owens ST. Outcomes for patients with unbalanced atrioventricular septal defects. Pediatr Cardiol. 2009;30:431-5. 
18. Alsoufi B, McCracken C, Kanter K, Shashidharan S, Border W, Kogon B. Outcomes of multistage palliation of infants with single ventricle and atrioventricular septal defect. World J Pediatr Congenit Heart Surg. 2020;11:39-48.

19. Oladunjoye OO, Piekarski B, Banka P, Marx G, Breitbart RE, Del Nido PJ, et al. Staged ventricular recruitment in patients with borderline ventricles and large ventricular septal defects. J Thorac Cardiovasc Surg. 2018;156:254-64.

20. Ono M, Cleuziou J, Pabst von Ohain J, Beran E, Burri M, Strbad M, et al. Atrioventricular valve regurgitation in patients undergoing total cavopulmonary connection: impact of valve morphology and underlying mechanisms on survival and reintervention. J Thorac Cardiovasc Surg. 2018;155:701-9.

21. Imai Y, Seo K, Terada M, Aoki M, Shin'oka T, Ohta J, et al. Valvular repair for atrioventricular regurgitation in complex anomalies in modified Fontan procedure with reference to a single ventricle associated with a common atrioventricular valve. Semin Thorac Cardiovasc Surg Pediatr Card Surg Annu. 1999;2:5-19.

22. Kotani Y, Chetan D, Atlin CR, Mertens LL, Jegatheeswaran A, Caldarone CA, et al. Longevity and durability of atrioventricular valve repair in singleventricle patients. Ann Thorac Surg. 2012;94:2061-9.

23. Laux D, Vergnat M, Lambert V, Gouton M, Ly M, Peyre M, et al. Atrio-ventricular valve regurgitation in univentricular hearts: outcomes after repair. Interact Cardiovasc Thorac Surg. 2015;20:622-9.

24. Wong DJ, Iyengar AJ, Wheaton GR, Ramsay JM, Grigg LE, Horton S, et al. Long-term outcomes after atrioventricular valve operations in patients undergoing single-ventricle palliation. Ann Thorac Surg. 2012;94:606-13.

25. Nakata T, Fujimoto Y, Hirose K, Tosaka Y, Ide Y, Tachi M, et al. Atrioventricular valve repair in patients with functional single ventricle. J Thorac Cardiovasc Surg. 2010;140:514-21.
26. King G, Winlaw DS, Alphonso N, Andrews D, Finucance K, Konstantinov IE, et al. Atrioventricular valve closure in Fontan palliation. Eur J Cardiothorac Surg. 2020;57:945-50.

27. Oku H, Iemura J, Kitayama H, Saga T, Shirotani H. Bivalvation with bridging for common atrioventricular valve regurgitation in right isomerism. Ann Thorac Surg. 1994;57:1324-6.

28. Takayama T, Nagata N, Miyairi T, Abe M, Koseni K, Yoshimura Y. Bridging annuloplasty for common atrioventricular valve regurgitation. Ann Thorac Surg. 1995;59:1003-5.

29. Sughimoto K, Konstantinov IE, Brizard CP, d'Udekem Y. Polytetrafluoroethylene bridge for atrioventricular valve repair in single-ventricle palliation. $J$ Thorac Cardiovasc Surg. 2015;149:641-3.

30. Konstantinov IE, Sughimoto K, Brizard CP, d'Udekem Y. Single ventricle: repair of atrioventricular valve using the bridging technique. Multimed Man Cardiothorac Surg. 2015;2015:mmv027.

31. Misumi Y, Hoashi T, Kagisaki K, Kitano M, Kurosaki K, Shiraishi I, et al. Longterm outcomes of common atrioventricular valve plasty in patients with functional single ventricle. Interact Cardiovasc Thorac Surg. 2014;18:259-65.

32. He F, Jiao Y, Ma K, Hua Z, Zhang H, Yan J, et al. Outcomes of common atrioventricular valve repair in patients with single-ventricle physiology-indication, timing and repair techniques. Circ J. 2019;83:647-53.

Key Words: atrioventricular septal defect, atrioventricular valve, fibrous skeleton of the heart, Fontan, univentricular circulation 


\section{Atrioventricular valve surgery: Recent Articles From AATS Journals}
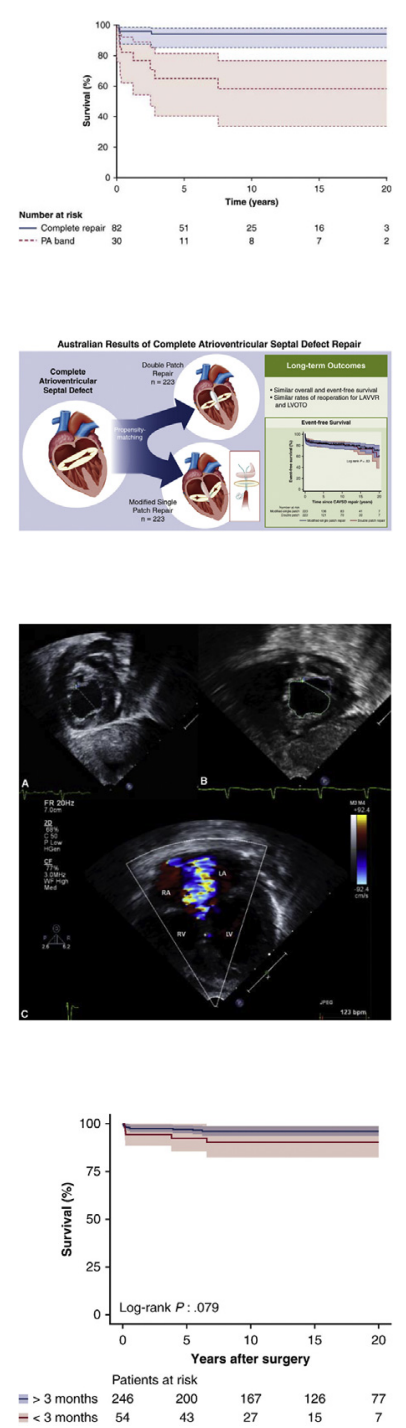

JTCvS: Early repair of complete atrioventricular septal defect has better survival than stages repair after pulmonary artery banding: A propensity score-matched study. Buratto E, Hu Thomas, Lui A, d'Udekem Y, Brizard CP, Konstantinov IE. J Thorac Cardiovasc Surg. 2021 [In Press].

Commentary: To band or not to band-is that really the question? Husain SA. J Thorac Cardiovasc Surg. 2021 [n Press].

Commentary: Early repair of complete atrioventricular septal defect is the forward move. Clark JB. J Thorac Cardiovasc Surg. 2021 [In Press].

JTCVS: Complete atrioventricular septal defect repair in Australia: Results over 25 years. Fong LS, Betts K, Bell D, Konstantinov IE, Nicholson IA, Winlaw DS, Orr Y. J Thorac Cardiovasc Surg. 2020;159(3):1014-1025.

Commentary: Atrioventricular canal repair: Surgeon preference reigns supreme. Lehenbauer DG, Calhoon J. J Thorac Cardiovasc Surg. 2020;159(3):1026-1027.

Commentary: This case is closed. Backer CL. J Thorac Cardiovasc Surg. 2020;159(3):1028.

JTCVS: Pulmonary artery banding in complete atrioventricular septal defect. Devlin PJ, Jegatheeswaran A, McCrindle BW, Karamlou T, Blackstone EH, Williams WG, DeCampli WM, Mertens L, Fackoury CT, Eghtesady P, Jacobs JP, Baffa JM, Fleishman CE, DodgeKhatami A, Pizarro C, Pourmoghadam K, Cohen MS, Meyer DB, Overman DM. J Thorac Cardiovasc Surg. 2020;159(4):1493-1503.

Commentary: Pulmonary artery banding in infants with atrioventricular septal defect, valid strategy or backward move? Alsoufi B. J Thorac Cardiovasc Surg. 2020;159(4):1504-1506. Commentary: No Harm, no foul-Staged pulmonary artery banding in complete canal defects. Eckhauser A. J Thorac Cardiovasc Surg. 2020;159(4):1507.

JTCVS: Long-term outcome after early repair of complete atrioventricular septal defect in young infants. Ramgren JJ, Nozohoor S, Zindovic I, Gustafsson R, Hakacova N, Sjögren J. J Thorac Cardiovasc Surg. 2021 [In Press].

Commentary: Repair of complete atrioventricular septal defect: The bar has been set. Overman DM. J Thorac Cardiovasc Surg. 2021 [In Press].

Commentary: Complete atrioventricular septal defect in young infants: The advantages of early repair. Burkhart HM. J Thorac Cardiovasc Surg. 2021 [In Press].

Commentary: Regionalization = Excellence. Backer CL. J Thorac Cardiovasc Surg. 2021 [In Press]. 